\title{
Trigeminal autonomic cephalalgias: fancy term or constructive change to the IHS classification?
}

\section{P J Goadsby}

\section{A classification based on pathophysiology is a useful aid to differential diagnosis and effective treatment planning}

$\mathrm{F}$ or the neurologist faced with the day to day grind of clinical work a change to terminology may seem like the academics "at it again". I will try to set out this change and illustrate a physiology that may be attractive to understand, and hopefully one that enhances, clinical practice. Appreciating the physiology of the trigeminalautonomic reflex can make patients presenting with varying degrees of cranial autonomic activation, such as lacrimation, conjunctival injection, nasal congestion or rhinorrhoea and the like, comprehensible at the bedside. ${ }^{1}$

The trigeminal autonomic cephalalgias (TACs) is a grouping of headache syndromes recognised in the second edition of the International Headache Society (IHS) classification. ${ }^{2}$ The term was coined to reflect a part of the pathophysiology of these conditions that is a common thread-that is, excessive cranial parasympathetic autonomic reflex activation to nociceptive input in the ophthalmic division of the trigeminal nerve. ${ }^{1}$ The TACs are classified in section III of the second edition of the classification, ${ }^{2}$ and include cluster headache, ${ }^{3}$ paroxysmal hemicrania, and short lasting unilateral neuralgiform headache attacks with conjunctival injection and tearing (SUNCT). ${ }^{4}$ In an early draft, hemicrania continua was included ${ }^{5}$ but this was finally classified in section IV. I will briefly review the underlying physiology of the trigeminal-autonomic reflex that underpins these conditions and set out their classification and differential diagnosis. I will point out some limitations and some directions for future research. Their therapy is beyond the scope of the present paper, but it has been recently reviewed. ${ }^{4}$

\section{PATHOPHYSIOLOGY OF TACs}

Any pathophysiological construct for TACs must account for the two major shared clinical features characteristic of the various conditions that comprise this group: trigeminal distribution pain and ipsilateral cranial autonomic features. ${ }^{1}$ The pain producing innervation of the cranium projects through branches of the trigeminal and upper cervical nerves ${ }^{67}$ to the trigeminocervical complex ${ }^{8}$ from whence nociceptive pathways project to higher centres. ${ }^{9}$ A reflex activation of the cranial parasympathetic outflow provides the efferent loop.

\section{Experimental studies}

Stimulation of the trigeminal ganglion in the cat produces cranial vasodilation and neuropeptide release, notably calcitonin gene related peptide (CGRP) and substance $P .^{10}$ The dilation is mediated by antidromic activation of the trigeminal nerve $(20 \%$ of the effect) and orthodromic activation through the cranial parasympathetic outflow via the facial (VIIth) cranial nerve, for the other $80 \%{ }^{11}$ The afferent arm of the trigeminal-parasympathetic reflex traverses the trigeminal root, ${ }^{11}$ synapses in the trigeminal nucleus and then projects to neurones of the superior salivatory nucleus in the pons. ${ }^{12}$ There is a glutamatergic excitatory receptor in the pontine synapse $\mathrm{s}^{13}$ and projection via the facial nerve ${ }^{14}$ without synapse in the geniculate ganglion. The greater superficial petrosal nerve supplies classic autonomic preganglionic fibres to the sphenopalatine (pterygopalatine in humans) and otic ganglia. ${ }^{15}$ The sphenopalatine synapse involves a nicotinic ganglion that is hexamethonium sensitive. ${ }^{15}$ VIIth cranial nerve activation is associated with release of vasoactive intestinal polypeptide (VIP) $)^{16}$ and blocked by VIP antibodies. ${ }^{17}$ Changes in the flow of blood in the brain depend on the frequency of stimulation ${ }^{18}{ }^{19}$ and are independent of cerebral metabolism. ${ }^{20}$ There is VIP in the sphenopalatine ganglion, ${ }^{21}$ as well as nitric oxide synthase, which is also involved in the vasodilator mechanism. ${ }^{22}$

\section{Human studies}

The basic science work outlined above implies an integral role for the ipsilateral trigeminal nociceptive pathways in TACs and predicts in some patients cranial parasympathetic autonomic activation. The ipsilateral autonomic features seen clinically are consistent with cranial parasympathetic activation (lacrimation, rhinorrhoea, nasal congestion, and eyelid oedema) and sympathetic hypofunction (ptosis and miosis). The latter is likely to be a neurapraxic effect of carotid wall swelling ${ }^{23} 24$ with cranial parasympathetic activation. Some degree of cranial autonomic symptomatology is, therefore, a normal physiological response to cranial nociceptive input. $^{25-27}$ Indeed other primary headaches, notably migraine, ${ }^{28}$ or patients with facial pain, such as trigeminal neuralgia, ${ }^{29}$ would be expected to have cranial autonomic activation, and they do. The distinction between the TACs and other headache syndromes is the degree of cranial autonomic activation, not its presence alone. ${ }^{30}$ This is why some patients with migraine have minor cranial autonomic activation that leads to the term cluster-migraine, when most such patients have migraine with cranial autonomic activation.

\section{Permitting trigeminal- parasympathetic activation}

What is the basis for the cranial autonomic symptoms being so prominent in the TACs? Is it due to a central disinhibition of the trigeminal-autonomic reflex $?^{30}$ Functional imaging studiespositron emission tomography studies in cluster headache $\mathrm{e}^{31-33}$ and a functional magnetic resonance imaging (MRI) study in SUNCT syndrome ${ }^{34}$ has demonstrated ipsilateral posterior hypothalamic activation. Posterior hypothalamic activation seems specific to these syndromes and is not seen in episodic $^{35-37}$ or chronic ${ }^{38}$ migraine, or in experimental ophthalmic trigeminal distribution head pain..$^{39}$ There are direct hypothalamic-trigeminal connections ${ }^{40}$ and the hypothalamus is known to have a modulatory role on the nociceptive and autonomic pathways, specifically trigeminovascular nociceptive pathways. ${ }^{41}$ Hence, cluster headache and SUNCT syndrome are probably due to an abnormality in the region of the hypothalamus (fig 1) with subsequent trigeminovascular and cranial autonomic activation. Imaging data with paroxysmal hemicrania are keenly awaited. Cranial autonomic features are not invariably linked with trigeminal pain and may persist after lesions of the trigeminal nerve.

\section{DIFFERENTIAL DIAGNOSIS OF}

\section{TACs}

The TACs need to be differentiated from secondary TAC producing lesions, from 

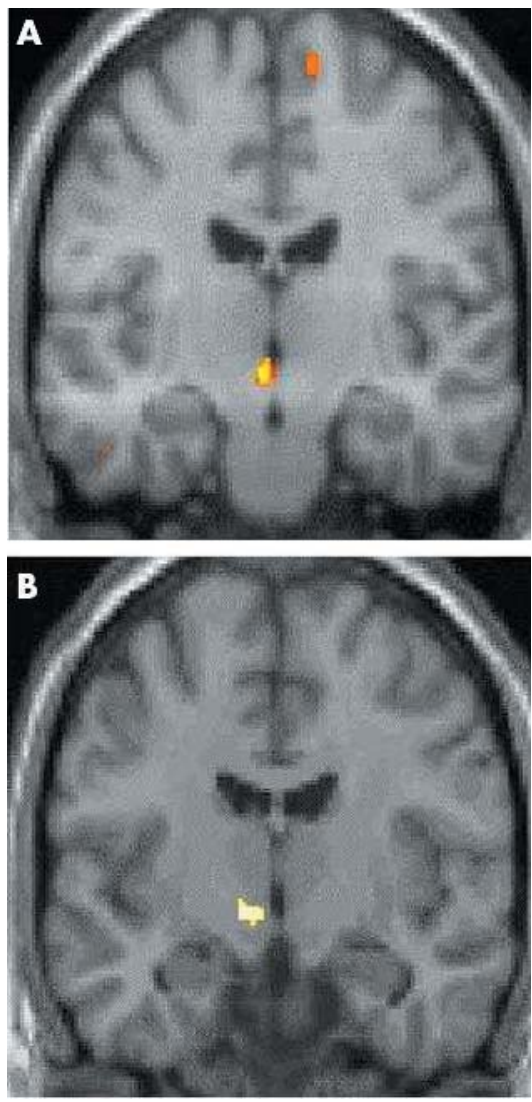

Figure 1 Brain imaging of two trigeminal autonomic cephalalgias. Changes in the posterior hypothalamic grey are revealed with (A) positron emission tomography in patients with chronic cluster headache ${ }^{31}$ and (B) with blood oxygen level dependent (BOLD)functional MRI in a patient with short lasting unilateral neuralgiform headache attacks with conjunctival injection and tearing (SUNCT) in whom multiple attacks were captured. ${ }^{34}$

other primary headaches, and from each other. The differentiation from secondary causes is not a problem if one images patients but can be extremely difficult if one does not. An MRI of the brain with attention to the pituitary fossa and cavernous sinus will detect most secondary causes. It is easy to make an argument given the rarity of paroxysmal hemicrania and SUNCT that MRI would be a reasonable part of the initial work-up of such patients. It is more complex for cluster headache. There are no clear studies, and our impression from a cohort that now exceeds 400 (the National Hospital for Neurology and Neurosurgery, London) is that MRI would detect no more than 1 in 100 cases of lesions in episodic cluster headache, so we cannot recommend its routine use. For chronic cluster headache, an MRI seems reasonable given that very difficult nature of the long term management and developments in neuromodulation as a treatment. $^{42}$

Table 1 Clinical features of the trigeminal autonomic cephalalgias (TACs)

\begin{tabular}{|c|c|c|c|}
\hline & Cluster headache & $\begin{array}{l}\text { Paroxysmal } \\
\text { hemicrania }\end{array}$ & SUNCT syndrome \\
\hline $\operatorname{Sex}(F: M)$ & $1: 4$ & $2: 1$ & $1: 2$ \\
\hline \multicolumn{4}{|l|}{ Pain } \\
\hline Type & Stabbing, boring & $\begin{array}{l}\text { Throbbing, boring, } \\
\text { stabbing }\end{array}$ & Burning, stabbing, sharp \\
\hline Severity & Severe to excruciating & Excruciating & Moderate to severe \\
\hline Site & Orbit, temple, face & Orbit, temple & Periorbital \\
\hline Attack frequency & $1 /$ alternate day- 8 daily & $1-40 /$ day & $1 /$ day-30/hour \\
\hline Duration of attack & $15-180$ minutes & 2-30 minutes & $5-240$ seconds \\
\hline Autonomic features & Yes & Yes & $\begin{array}{l}\text { Yes (prominent conjunctival } \\
\text { injection and lacrimation) }\end{array}$ \\
\hline Migrainous features* & Yes & Yes & Not \\
\hline Alcohol trigger & Yes & Occasional & No \\
\hline Indometacin effect & - & ++ & - \\
\hline
\end{tabular}

*Nausea, photophobia (often ipsilateral to the pain) or phonophobia.

tMay have photophobia ipsilateral to the pain.

SUNCT, Short lasting unilateral neuralgiform headache attacks with conjunctival injection and tearing.

Table 2 Cluster headache

3.1 Diagnostic criteria:

A At least five attacks fulfilling B-D

B Severe or very severe unilateral orbital, supraorbital and/or temporal pain lasting 15-180 minutes if untreated

C Headache is accompanied by at least one of the following:

(1) Ipsilateral conjunctival injection and/or lacrimation

(2) Ipsilateral nasal congestion and/or rhinorrhoea

(3) Forehead and facial sweating

(4) Ipsilateral eyelid oedema

(5) Ipsilateral forehead and facial sweating

(6) Ipsilateral miosis and/or ptosis

(7) A sense of restlessness or agitation

D Attacks have a frequency from one every other day to eight per day

E Not attributed to another disorder

3.1.1 Episodic cluster headache

Description: Occurs in periods lasting seven days to one year separated by pain free periods lasting one month or more

Diagnostic criteria:

A All fulfilling criteria A-E of 3.1

B At least two cluster periods lasting from 7 to 365 days and separated by pain free remissions of one month or more

3.1.2 Chronic cluster headache

Description: Attacks occur for more than one year without remission or with remissions lasting less than one month

Diagnostic criteria:

A All alphabetical headings of 3.1

B Attacks recur for more than one year without remission periods or with remission periods lasting less than one month

For other primary headaches, migraine is the single biggest problem in the differential diagnosis of cluster headache. Migraine can cluster and despite the best intentions of the IHS classification committee short attacks do occur. Cranial autonomic symptoms are well reported, ${ }^{28}$ and the neuropeptide changes are the same ${ }^{43}$ as in cluster headache. ${ }^{44}$ The occurrence of attacks together does not seem to have the seasonal preponderance that is so typical of cluster headache, ${ }^{45}{ }^{46}$ and this can be a useful differential diagnostic feature. I regard the term cluster-migraine as unhelpful and I am yet to see a convincing case of a distinct biological entity usefully described by this name. The criterion for the effect of movement was added to cluster headache to sharpen the difference with migraine.
The committee hoped this would draw attention to the fact that most cluster headache patients feel restless or agitated, ${ }^{47}$ whereas most migraine patients are quiescent, as IHS-I recognised. ${ }^{48}$

In clinical practice, this symptom, and the periodicity, are extremely helpful in differential diagnosis. The other feature of cluster headache, and this is a feature of TACs when compared with migraine, is that patients with TACs often complain of unilateral, homolateral photophobia, whereas patients with migraine more often complain of bilateral photophobia. Bilateral photophobia in patients with TAC could be speculated to occur in about $25 \%$ purely by the chance of them having some migrainous biology.

The TACs themselves (table 1) can often be differentiated by their attack 
Table 3 Paroxysmal hemicrania

3.2 Diagnostic criteria:

A At least 20 attacks fulfilling B-D

B Severe unilateral orbital, supraorbital, or temporal pain lasting 2-30 minutes

C Headache is accompanied by at least one of the following:

(1) Ipsilateral conjunctival injection and/or lacrimation

(2) Ipsilateral nasal congestion and/or rhinorrhoea

(3) Forehead and facial sweating

(4) Ipsilateral eyelid oedema

(5) Ipsilateral forehead and facial sweating

(6) Ipsilateral miosis and/or ptosis

D Attacks have a frequency above five per day for more than half the time, although periods with lower frequency may occur

E Attacks are prevented completely by therapeutic doses of indometacin

F Not attributed to another disorder

3.2.1 Episodic paroxysmal headache

Description: Occurs in periods lasting seven days to one year separated by pain free periods lasting one month or more

3.2.2 Chronic paroxysmal headache

Description: Attacks occur for more than one year without remission or with remissions lasting less than one month

length. This is certainly true when comparing cluster headache with SUNCT/short lasting unilateral neuralgiform headache attacks with cranial autonomic symptoms (SUNA). The IHS criteria for TACs does betray an uncomfortable biological naivety with regard to the timing. The A, C, D, E/F criteria are rather similar for each TAC (tables 2-4). It seems neat in some way to have SUNCT be up to four minutes long, paroxysmal hemicrania from two to 30 minutes and cluster headache from 15 minutes onwards. The overlap seems minimal. It almost goes without saying that this must be wrong in absolute terms, biology rarely provides such neat rules, but it does provide a useful way to identify cases of sufficiently similarity to make biologically meaningful studies.

Table 4 Short lasting unilateral neuralgiform headache attacks with conjunctival injection and tearing (SUNCT)

3.3 Diagnostic criteria:

A At least 20 attacks fulfilling criteria $B-E$

B Attacks of unilateral, orbital, supraorbital or temporal stabbing or pulsating pain last

5-240 seconds

C Pain is accompanied by ipsilateral conjunctival injection and lacrimation

D Attacks occur with a frequency from three to 200 per day

E Not attributed to another disorder

Table 5 Effects of treatment on trigeminal autonomic cephalalgias

\begin{tabular}{|c|c|c|c|}
\hline & Cluster headache & Paroxysmal hemicrania & SUNCT syndrome \\
\hline Indometacin effect & - & ++ & - \\
\hline Abortive treatment & $\begin{array}{l}\text { Sumatriptan } 6 \mathrm{mg} \mathrm{s} / \mathrm{c} \text { or } \\
20 \mathrm{mg} \text { nasal insufflation } \\
\text { Oxygen }\end{array}$ & Nil & Nil \\
\hline $\begin{array}{l}\text { Preventive } \\
\text { treatment }\end{array}$ & $\begin{array}{l}\text { Verapamil } \\
\text { Methysergide } \\
\text { Lithium } \\
\text { Prednisone }\end{array}$ & Indometacin & $\begin{array}{l}\text { Lamotrigine } \\
\text { Topiramate } \\
\text { Gabapentin }\end{array}$ \\
\hline
\end{tabular}

almost any study except natural history studies where they are ideally the starting point. A similar problem is how to refer to patients who have one type of TAC, typically an episodic form, and then evolve to the chronic form. The old classification differentiated primary from secondary chronic cluster headache depending on whether there was a period of episodic headache first. This argument would apply equally to chronic paroxysmal hemicrania. There seems little evidence that the clinical characteristics or therapeutic behaviour of primary or secondary chronic cluster headache are different, and the terminology secondary in headache parlance generally implies an underlying pathology. Moreover, the main clinical imperative when the timing alters would be review, perhaps with investigation, but this is a generic principle in headache management. For the moment the distinction has been dropped.

\section{Paroxysmal hemicrania (PH)}

The diagnosis of $\mathrm{PH}$ by the IHS criteria requires a response to indometacin. This is very difficult. It is not clear what the basis for the indometacin effect is, although it is perfectly clear that the effect is clinically very meaningful (table 5). Patients with $\mathrm{PH}$ who are treated with indometacin have an almost unbelievably spectacular resolution. This response seems so distinct that reserving the diagnosis of $\mathrm{PH}$ for these patients seems reasonable. Given varying sensitivity to indometacin, we have seen a requirement for a single dose given first thing in the morning of $300 \mathrm{mg}$ indometacin to produce a complete response-perhaps there are unrecognised dosing requirements. There is certainly a timing requirement and again we have seen patients turn off, but only after 10 days at the dose of $275 \mathrm{mg}$ daily.

\section{SUNCT}

For SUNCT the most immediate challenge must be to define the phenotype properly. We have seen patients who fulfil criteria for SUNA (table 6) but not SUNCT (see table 4). Typically the eye is not red, but we have also seen, for example external auditory canal swelling and periaural flushing as the sole cranial autonomic symptom, as has been reported for $\mathrm{PH}^{50}$ It seems possible, given the relative proportion of patients with cluster headache who have lacrimation and conjunctival injection as compared with other cranial autonomic symptoms, ${ }^{47}$ that these symptoms are for some reason biologically more likely. This is supported by the same relative changes being seen in experimentally induced head pain. ${ }^{51}$ 
Table 6 Short lasting unilateral neuralgiform headache attacks with cranial autonomic symptoms (SUNA)

\section{A 3.3 Diagnostic criteria:}

A At least 20 attacks fulfilling criteria B-E

B Attacks of unilateral orbital, supraorbital, or temporal stabbing pain lasting from two seconds to

10 minutes

C Pain is accompanied by one of:

(1) Conjunctival injection and/or tearing

(2) Nasal congestion and or rhinorrhoea

(3) Eyelid oedema

D Attacks occur with a frequency of one or more per day for more than half the time

E Not attributed to another disorder

A 3.3.1 Episodic SUNA

Description: SUNA attacks occurring for seven days to one year with pain free intervals longer than one month

A 3.3.2 Chronic SUNA

Description: At least two attack periods last seven days to one year separated by remission periods of less than one month (untreated)

Thus research criteria for a more encompassing syndrome are proposed (see table 6).

\section{CONCLUSION}

The TACs represent a great success story in headache. From a classification point of view, the syndromes share much biology so their agglomeration in section III draws attention to them and to the trigemino-parasympathetic reflex. It is highly desirable that headache classification moves to a more biological and pathophysiological basis and the TACs are a step in that direction. The TACs also represent excellent clinical opportunities to take a careful history and offer effective therapy to otherwise highly disabled, suffering patients. Lastly, further investigations of the TACs are bound to illuminate physiological processes whose understanding will be useful to the range of primary headache syndromes.

J Neurol Neurosurg Psychiatry 2005;76:301-305.

doi: 10.1136/jnnp.2004.036012

Correspondence to: Prof P J Goadsby, Institute of Neurology, Queen Square, London WCIN 3BG, UK; peterg@ion.ucl.ac.uk

Competing interests: PJG is a Wellcome Trust Senior Research Fellow.

\section{REFERENCES}

1 Goadsby PJ, Lipton RB. A review of paroxysmal hemicranias, SUNCT syndrome and other short-lasting headaches with autonomic features, including new cases. Brain 1997; 120:193-209.

2 Headache Classification Committee of the International Headache Society. The International Classification of Headache Disorders, 2nd edn. Cephalalgia 2004;24(suppl 1):1-160.

3 Goadsby PJ. Pathophysiology of cluster headache: a trigeminal autonomic cephalgia. Lancet Neurology 2002;1:37-43.

4 Matharu MS, Boes CJ, Goadsby PJ. Management of trigeminal autonomic cephalalgias and hemicrania continua. Drugs 2003:63:1637-77.
5 Olesen J. Revision of the International Headache Classification. An interim report. Cephalalgia 2001;21:261

$6 \mathrm{McNaughton} \mathrm{FL}$, Feindel WH. Innervation of intracranial structures: a reappraisal. In: Rose FC, ed. Physiological aspects of Clinical Neurology. Oxford: Blackwell Scientific Publications, 1977:279-93.

7 Feindel W, Penfield W, McNaughton F. The tentorial nerves and localization of intracranial pain in man. Neurology 1960;10:555-63.

8 Goadsby PJ, Hoskin KL. The distribution of trigeminovascular afferents in the nonhuman primate brain Macaca nemestrina: a c-fos immunocytochemical study. J Anat 1997; 190:367-75.

9 May A, Goadsby PJ. The trigeminovascular system in humans: pathophysiological implications for primary headache syndromes of the neural influences on the cerebral circulation. J Cereb Blood Flow Metab 1999;19:1 15-27.

10 Goadsby PJ, Edvinsson L, Ekman R. Release of vasoactive peptides in the extracerebral circulation of man and the cat during activation of the trigeminovascular system. Ann Neurol 1988:23:193-6.

11 Lambert GA, Bogduk N, Goadsby PJ, et al. Decreased carotid arterial resistance in cats in response to trigeminal stimulation. J Neurosurg 1984:61:307-15.

12 Spencer SE, Sawyer WB, Wada H, et al. CNS projections to the pterygopalatine parasympathetic preganglionic neurons in the rat: a retrograde transneuronal viral cell body labeling study. Brain Res 1990;534:149-69.

13 Nakai M, Tamaki K, Ogata J, et al. Parasympathetic cerebrovascular center of the facial nerve. Circ Res 1993:72:470-5.

14 Goadsby PJ, Lambert GA, Lance JW. Effects of locus coeruleus stimulation on carotid vascular resistance in the cat. Brain Res 1983:278: 175-83

15 Goadsby PJ, Lambert GA, Lance JW. The peripheral pathway for extracranial vasodilatation in the cat. J Auton Nerv Sys 1984:10:145-55

16 Goadsby PJ, Shelley S. High frequency stimulation of the facial nerve results in local cortical release of vasoactive intestinal polypeptide in the anesthetised cat. Neurosci Lett 1990; 112:282-9.

17 Goadsby PJ, Macdonald GJ. Extracranial vasodilatation mediated by VIP (vasoactive intestinal polypeptide). Brain Res 1985;329:285-8.

18 Goadsby PJ. Characteristics of facial nerve elicited cerebral vasodilatation determined with laser Doppler flowmetry. Am J Physiol 1991;260:R255-R262.

19 Seylaz J, Hara H, Pinard E, et al. Effect of stimulation of the sphenopalatine ganglion on cortical blood flow in the rat. $J$ Cereb Blood Flow Metab 1988;8:875-8.
20 Goadsby PJ. Effect of stimulation of the facial nerve on regional cerebral blood flow and glucose utilization in cats. Am J Physiol 1989;257:R517-R521.

21 Uddman R, Tajti J, Moller S, et al. Neuronal messengers and peptide receptors in the human sphenopalatine and otic ganglia. Brain Res 1999;826: 193-9.

22 Goadsby PJ, Uddman R, Edvinsson L. Cerebral vasodilatation in the cat involves nitric oxide from parasympathetic nerves. Brain Res 1996;707:110-18.

23 Ekbom K, Greitz T. Carotid angiography in cluster headache. Acta Radiol 1970;10:177-86.

24 May A, Buchel C, Bahra A, et al. Intra-cranial vessels in trigeminal transmitted pain: a PET Study. Neurolmage 1999;9:453-60.

25 Drummond PD, Lance JW. Pathological sweating and flushing accompanying the trigeminal lacrimation reflex in patients with cluster headache and in patients with a confirmed site of cervical sympathetic deficit. Evidence for parasympathetic cross-innervation. Brain paras: 115:1429-45.

26 Drummond PD. Autonomic disturbance in cluster headache. Brain 1988;111:1199-209.

27 May A, Buchel C, Turner R, et al. MRangiography in facial and other pain: neurovascular mechanisms of trigeminal sensation. J Cereb Blood Flow Metab 2001;21:1171-6.

28 Barbanti P, Fabbrini G, Pesare $M$, et al Unilateral cranial autonomic symptoms in migraine. Cephalalgia 2002;22:256-9

29 Benoliel R, Sharav Y. Trigeminal neuralgia with lacrimation or SUNCT syndrome? Cephalalgia 1998; 18:85-90.

30 Goadsby PJ, Matharu MS, Boes CJ. SUNCT syndrome or trigeminal neuralgia with lacrimation. Cephalalgia 2001;21:82-3.

31 May A, Bahra A, Buchel C, et al. Hypothalamic activation in cluster headache attacks. Lancet 1998;352:275-8.

32 May A, Bahra A, Buchel C, et al. PET and MRA findings in cluster headache and MRA in experimental pain. Neurology 2000;55:1328-35

33 Sprenger T, Boecker H, Tolle TR, et al. Specific hypothalamic activation during a spontaneous cluster headache attack. Neurology 2004:62:516-17.

34 May A, Bahra A, Buchel C, et al. Functional MRI in spontaneous attacks of SUNCT: short-lasting neuralgiform headache with conjunctival injection and tearing. Ann Neurol 1999:46:791-3.

35 Weiller C, May A, Limmroth V, et al. Brain stem activation in spontaneous human migraine attacks. Nat Med 1995; 1:658-60.

36 Bahra A, Matharu MS, Buchel C, et al. Brainstem activation specific to migraine headache. Lancet 2001;357:1016-17.

37 Afridi S, Giffin NJ, Kaube H, et al. A PET study in spontaneous migraine. Arch Neurol 2004 (in press).

38 Matharu MS, Bartsch T, Ward N, et al. Central neuromodulation in chronic migraine patients with suboccipital stimulators: a PET study. Brain 2004; 127:220-30.

39 May A, Kaube H, Buechel C, et al. Experimental cranial pain elicited by capsaicin: a PET-study. Pain 1998;74:61-6.

40 Malick A, Burstein R. Cells of origin of the trigeminohypothalamic tract in the rat. J Comp Neurol 1998:400:125-44.

41 Bartsch T, Levy MJ, Knight YE, et al. Differential modulation of nociceptive dural input to [hypocretin] Orexin A and B receptor activation in the posterior hypothalamic area. Pain 2004; 109:367-78.

42 Franzini A, Ferroli $P$, Leone $M$, et al. Stimulation of the posterior hypothalamus for treatment of chronic intractable cluster headaches. The first reported series. Neurosurgery 2003;52:1095-101.

43 Goadsby PJ, Edvinsson L, Ekman R. Vasoactive peptide release in the extracerebral circulation of humans during migraine headache. Ann Neurol 1990;28:183-7.

44 Goadsby PJ, Edvinsson L. Human in vivo evidence for trigeminovascular activation in cluster headache. Brain 1994;117:427-34. 
45 Kudrow L. Cluster headache: Mechanisms and Management. Oxford: Oxford University Press, 1980.

46 Siaastad O. Cluster Headache Syndrome. London: WB Saunders, 1992

47 Bahra A, May A, Goadsby PJ. Cluster headache: a prospective clinical study in 230 patients with diagnostic implications. Neurology 2002;58:354-61.
48 International Headache Society. Classification and diagnostic criteria for headache disorders, cranial neuralgias and facial pain. Cephalalgia 1988;8(suppl 7): 1-96.

49 Sjaastad O, Bakketeig LS. Cluster headache prevalence. Vaga study of headache epidemiology. Cephalalgia 2003;23:528-33.
50 Boes CJ, Swanson JW, Dodick DW. Chronic paroxysmal hemicrania presenting as otalgia with a sensation of external acoustic meatus obstruction: two cases and a pathophysiologic hypothesis. Headache 1998;38:787-91.

51 Frese A, Evers S, May A. Autonomic activation in experimental trigeminal pain. Cephalalgia 2003;23:67-8.

\section{Action of cholinesterase inhibitors in patients' brains}

\section{K Herholz}

\section{Cholinesterase inhibitors in patients' brains}

t holinesterase (ChE) inhibitors are the only class of drug that have consistently shown improvement in cognitive function in patients with mild to moderate Alzheimer's disease. Unfortunately, improvement is generally rather small. ${ }^{1}$ Recent clinical trials have caused considerable controversy about their actual benefit and indications. On one hand, some studies suggest more extensive use because improvement of cognitive function has also been observed in vascular dementia, dementia with Lewy bodies, and Parkinson's disease with dementia. However, on the other hand a recent study in community resident patients with mild to moderate Alzheimer's disease concluded that benefits were "below minimally relevant thresholds."

On the background of this confusing situation, studies are particularly welcome that provide clues as to how $\mathrm{ChE}$ inhibitors exert their moderate effect in patients and how we could increase their efficacy. In this issue, such information is provided in a study by Bohnen et al, (see page 315) which measured the actual inhibition of cortical acetylcholine esterase (AChE) activity by donepezil in vivo and studied the correlation of the degree of inhibition with the cognitive effects. Several observations were made that indicate directions for improving therapy.

The inhibition of cortical AChE activity by donepezil at the recommended dose of $10 \mathrm{mg}$ daily was rather low (on average 16-24\% depending on cortical regions) and it varied considerably among patients. Although somewhat higher values had been measured with a slightly different tracer by other authors cited in the paper, inhibition of human cerebral AChE is much less than observed in peripheral blood, ${ }^{4}$ which is in contrast to findings in rats. ${ }^{5}$ Thus, dosage, pharmacokinetics, or specific binding of the drug to human cerebral AChE appear to be suboptimal, and this had not become evident during preclinical and clinical phases of drug development and testing.

The study also indicates that the degree of cerebral AChE inhibition makes a clinical difference because it was significantly correlated with measures of executive function and attention. This indicates that it could indeed be worthwhile to increase inhibition in selected patients, e.g. by higher dosage if side effects permit. It is expected that similar positron emission tomography (PET) studies will be performed to measure inhibition of cerebral butyrylcholine esterase (BChE) for selection and development of drugs that achieve higher effective levels of acetylcholine by additional inhibition of this degradation pathway. ${ }^{6}$

Another interesting aspect is that the relatively small inhibition effects were observed in temporal and parietal association cortex-structures that are thought to be of pivotal importance for episodic and semantic memory-that did not benefit significantly from treatment in this and other studies. One would wish to see similar studies with other ChE inhibitors to determine whether this is a property of the entire class of drugs.

It is gratifying that such direct in vivo assessments of pharmacological action are happening now, which means that we do not depend solely on large trials with clinical outcome measures that are, of course, of utmost clinical importance but often tell very little about the mechanisms that explain interindividual variation. One can hope that this will ultimately provide rational means to improve treatment of individuals, which is in the primary interest of patients and doctors.

J Neurol Neurosurg Psychiatry 2005;76:305. doi: 10.1136/jnnp.2004.048405

Correspondence to: K Herholz, Department of Neurology, University of Cologne, and MaxPlanck-Institute for Neurological Research, Gleuler Str. 50, 50931 Cologne, Germany; karl.herholz@pet.mpin-koeln.mpg.de

Competing interests: none declared

\section{REFERENCES}

1 Rockwood K. Size of the treatment effect on cognition of cholinesterase inhibition in Alzheimer's disease. J Neurol Neurosurg Psychiatry 2004;75:677-85.

2 Courtney C, Farrell D, Gray R, et al. Long-term donepezil treatment in 565 patients with Alzheimer's disease (AD2000): randomised double-blind trial. Lancet 2004;363:2105-15.

3 Bohnen NI, Kaufer DI, Hendrickson R, et al. Degree of inhibition of cortical acetylcholinesterase activity and cognitive effects by donepezil treatment in Alzheimer's disease. J Neurol Neurosurg Psychiatry 2005:76:315-9.

4 Kuhl DE, Minoshima S, Frey KA, et al. Limited donepezil inhibition of acetylcholinesterase measured with positron emission tomography in living Alzheimer cerebral cortex. Ann Neurol 2000;48:391-5.

5 Kosasa T, Kuriya Y, Matsui K, et al. Inhibitory effects of donepezil hydrochloride (E2020) on cholinesterase activity in brain and peripheral tissues of young and aged rats. Eur J Pharmacol 1999:386:7-13.

6 Darvesh S, Walsh R, Kumar R, et al. Inhibition of Human Cholinesterases by Drugs Used to Treat Alzheimer Disease. Alzheimer Dis Assoc Disord 2003;17:117-26. 
Recreational cannabis

\section{Recreational cannabis use: not so harmless!}

\section{Deplanque}

\section{Cannabis and stroke}

c annabis is currently the most widely used illicit drug in Western populations. ${ }^{1}$ The question of whether or not it should remain prohibited is under debate in many European countries. Possible adverse health effects play an important role in this debate. The classical anxiolytic, sedative, analgesic, and psychedelic properties of cannabis are well known, ${ }^{1}$ but it has recently been suggested that it may also induce cerebrovascular disease. ${ }^{2}$ Now for the first time, Mateo et al have shown (this issue, see page 435) that a causal relation with cerebrovascular events is highly plausible. The major argument in favour of this is that the events only occurred during periods when the patient was consuming cannabis, and this is a major criterion of adverse drug reaction monitoring. ${ }^{3}$

Several possible mechanisms are discussed by the authors, the most likely being a drug induced vasculopathy. Others include postural hypotension with secondary impairment of the autoregulation of cerebral blood flow, atrial fibrillation, other arrhythmias, and vasospasm. ${ }^{2}{ }^{4}$ Though concomitant alcohol consumption may be a confounder, the absence of any proven cause, particularly the absence of haemodynamic or cardiac abnormalities, and the presence of multiple infarcts associated with narrowing of the intracranial arteries strongly suggest a toxic vasculopathy. The long duration of these alterations argues in favour of a drug induced vasculitis rather than vasospasm. Such a vasculitis has already been described in peripheral vessels as a result of chronic cannabis consumption, with many similarities to Buerger's disease. ${ }^{5}$ In the present case, the patient was not a regular user and both the arterial abnormalities and the time course of the disease suggest an immuno-allergic vasculitis.

The systemic effects of natural cannabis compounds ( $\Delta^{9}$-tetrahydrocannabinol, $\Delta^{8}$-tetrahydrocannabinol, canna binol, and cannabidiol) are primarily mediated by the activation of cannabinoid receptors $\left(\mathrm{CB}_{1}\right.$ and $\left.\mathrm{CB}_{2}\right)$, which are present in various tissues including the brain, cells of the immune system, blood vessels, and heart. ${ }^{1}$ Apart from the vasoactive properties of cannabinoids, it is also possible that a central nervous system vasculitis could result from a dysfunction of the immune system. ${ }^{6}$ It remains to be determined whether the immunomodulatory effects of cannabinoids could be involved as a mechanism of cannabis induced vasculitis through their action on $\mathrm{CB}_{2}$ receptors. ${ }^{1}$ The very low frequency of such complications ${ }^{2}$ may reflect a genetic predisposition in a few individuals. ${ }^{6}$ Better identification of patients with cannabis related strokes may lead to epidemiological case-control studies that include genomic investigations. In that recreational cannabis use appears not to be as harmless as was thought, there is a need to improve public information. The therapeutic potential of cannabis and its derivatives should be rigorously evaluated and the benefit to risk ratio taken into account before authorising their medical use.

J Neurol Neurosurg Psychiatry 2005;76:306. doi: 10.1136/jnnp.2004.059931

Correspondence to: Dr Dominique Deplanque, Department of Pharmacology, Faculty of Medicine, 59045 Lille cedex, France; d-deplanque@chru-lille.fr

Competing interests: none declared

\section{REFERENCES}

1 Ashton $\mathrm{CH}$. Pharmacology and effects of cannabis: a brief review. Br J Psychiatry 2001;178:101-6.

2 Moussouttas M. Cannabis use and cerebrovascular disease. Neurologist 2004; 10:47-53.

3 Moore N, Biour M, Paux G, et al. Adverse drug reaction monitoring: doing it the French way. Lancet 1985;ii:1056-8.

4 Sidney S. Cardiovascular consequences of marijuana use. J Clin Pharmacol 2002;42(suppl 11):64-70S.

5 Disdier P, Granel B, Serratrice J, et al. Cannabis arteritis revisited - ten new case reports. Angiology 2001;52:1-5.

6 Kelley RE. CNS vasculitis. Front Biosci 2004;9:946-55. 